Çukurova Üniversitesi Mühendislik Mimarlık Fakültesi Dergisi, 33(1), ss. 107-116, Mart 2018

Çukurova University Journal of the Faculty of Engineering and Architecture, 33(1), pp. 107-116, March 2018

\title{
Yüksek Verimli Transformatörlerin Yatırım Geri Dönüş Sürelerinin İncelenmesi
}

\author{
Hüzeyfe DOGRUKAN ${ }^{1}$, Ahmet TEKE ${ }^{* 2}$, Lütfü SARIBULUT ${ }^{3}$ \\ ${ }^{1,3}$ Adana Bilim Teknoloji Üniversitesi, Mühendislik Fakültesi, Elektrik Elektronik Mühendisliği \\ Bölümü, Adana \\ ${ }^{2}$ Çukurova Üniversitesi, Mühendislik Fakültesi, Elektrik Elektronik Mühendisliği Bölümü, \\ Adana
}

Geliş tarihi: $10.01 .2018 \quad$ Kabul tarihi: 14.03 .2018

$\ddot{\mathbf{O z}}$

Elektrik dağıtım şebekesinde kullanılan 15 yaş ve üstü transformatörlerin teknik kayıplarının yüksek olması nedeniyle verimlilikleri düşüktür. Enerji verimliliğinin önemini artırması ve teknolojik gelişmeler sayesinde ülkemizde yüksek verimli transformatörler üretilmeye başlanmıştır. Bu çalışmayla literatürde ilk defa Nisan 2018'de üretime başlanacak daha yüksek verimli transformatörlerin, dağıtım şebekesinde kullanılan ve 2005 ve öncesi imal yılına sahip transformatörlerle değişiminin kamu ve özel şirketlere göre yatırım geri dönüş süreleri incelenmiştir. Transformatörlerdeki teknik kayıplarının azaltılmasıyla, elektrik şebekesindeki veriminin artması ve sera gazı emisyonunda azalma sağlanması da gerçekleşecektir.

Anahtar kelimeler: Transformatör kayıpları, Yüksek verimli transformatör, Enerji verimliliği

\section{Investigation of Investment Return Periods for High Efficiency Transformer}

\begin{abstract}
Transformers over 15 years old used in electricity distribution network have low efficiency due to high technical losses. High efficiency transformers are started to produce in our country with the help of technological developments and increasing importance of energy efficiency. With this study, the investment turnaround periods of high efficiency transformers to be started production in April 2018, transformers used in the distribution network and transformers with production year 2005 and before have been examined according to public and private companies for the first time in the published literature. Reducing the technical losses on transformers, the increase on distribution network efficiency and reduction on greenhouse gas emissions will be ensured.
\end{abstract}

Keywords: Transformer losses, High efficiency transformers, Energy efficiency

*Corresponding author (Sorumlu yazar): Ahmet TEKE, ahmetteke@cu.edu.tr 


\section{GíRiș}

Transformatörler, enerji şebekesinde elektrik enerjisini farklı gerilim seviyelerine dönüștüren elektrik makinalarıdır. Her ne kadar çalışma verimleri oldukça yüksek olsa da, ulaşılan yüksek güç değerleri ve enerji şebekesinde var olan toplam transformatör sayısı dikkate alındığında, transformatör kayıplarının azaltılması amacıyla yapılan çalışmalar önemini korumaktadır [1]. Ülkemizde 21 adet Dağıtım şirketi vardır ve bu dağıtım şirketleri satın alacakları malzemeleri Türkiye Elektrik Dağıtım A.Ş.'nin (TEDAŞ) yayınladığ1 teknik şartnamelere uygun almak zorundadır. 2016 yılı Elektrik piyasası raporuna göre Türkiye'de toplam 436.299 adet dağıtım transformatörü bulunmaktadır [2].
Transformatörler belirli standartlara ve tüketici isteklerine göre üretilmektedir. Türkiye'de ise dağıtım transformatörleri ilk olarak 1995 yılında yayınlanan TEDAŞ-MYD/95-012 şartnamesi ile belirli standartları referans alınarak dağıtım şebekesinde kullanılacak transformatörlerin standartları belirlenmiştir. Transformatörlerde boşta (çekirdek) ve yükte (sargi) çalışma olmak üzere 2 farklı teknik kayıp görülmektedir. 19962018 yılları arasında dağıtım transformatörlerinin boşta ve yükte kayıpların değişimi Çizelge 1'de görülmektedir [3]. 2005 y1lında üretilen 33-kV,1000-kVA bir transformatörün teknik kayb1 toplam gücün \%1,25'i iken, 2018 y1lında üretilen $33-\mathrm{kV}, 1000-\mathrm{kVA}$ bir transformatörde bu kayıp $\% 0,92$ olacaktır. Transformatör teknik kayıplarındaki azalma \%33'tür.

Çizelge 1. TEDAŞ teknik şartnamelerinde transformatörün boşta ve yükte kayıplarındaki yıllara göre değișim

\begin{tabular}{|c|c|c|c|c|c|c|c|}
\hline \multicolumn{8}{|c|}{ Transformatör kayıplarındaki değişim 2005-2018 } \\
\hline \multirow{3}{*}{$\begin{array}{l}\text { İşletme } \\
\text { Gerilimi } \\
(\mathrm{kV})\end{array}$} & \multirow{3}{*}{$\begin{array}{l}\text { Güç } \\
\text { (kVA) }\end{array}$} & \multicolumn{2}{|c|}{ İlk Durum } & \multicolumn{2}{|c|}{ 1. Revize } & \multicolumn{2}{|c|}{ 2. Revize } \\
\hline & & \multicolumn{2}{|c|}{ Ocak-2005 12.C } & \multicolumn{2}{|c|}{ Ocak-2013 12.E } & \multicolumn{2}{|c|}{$\begin{array}{l}\text { Nisan-2017 12.F (Nisan } \\
\text { 2018'den sonra geçerlidir.) }\end{array}$} \\
\hline & & $\begin{array}{c}\text { Boşta } \\
\text { Kayıp (W) }\end{array}$ & $\begin{array}{c}\text { Yükte } \\
\text { Kayıp (W) }\end{array}$ & $\begin{array}{c}\text { Boşta } \\
\text { Kayı (W) }\end{array}$ & $\begin{array}{c}\text { Yükte } \\
\text { Kayıp (W) }\end{array}$ & $\begin{array}{c}\text { Boşta } \\
\text { Kayıp (W) }\end{array}$ & $\begin{array}{l}\text { Yükte Kayıp } \\
\text { (W) }\end{array}$ \\
\hline \multirow{11}{*}{15,8} & 25 & & & & & 70 & 600 \\
\hline & 50 & 190 & 1100 & 90 & 750 & 90 & 750 \\
\hline & 100 & 320 & 1750 & 145 & 1250 & 145 & 1250 \\
\hline & 160 & 460 & 2350 & 210 & 1700 & 210 & 1700 \\
\hline & 250 & 650 & 3250 & 300 & 2350 & 300 & 2350 \\
\hline & 400 & 930 & 4600 & 430 & 3250 & 430 & 3250 \\
\hline & 630 & 1300 & 6500 & 600 & 4600 & 600 & 4600 \\
\hline & 800 & 1500 & 8500 & 650 & 6000 & 650 & 6000 \\
\hline & 1000 & 1700 & 10500 & 770 & 7600 & 770 & 7600 \\
\hline & 1250 & 2100 & 13000 & 950 & 9500 & 950 & 9500 \\
\hline & 1600 & 2600 & 17000 & 1200 & 12000 & 1200 & 12000 \\
\hline \multirow{11}{*}{33} & 25 & & & & & 81 & 660 \\
\hline & 50 & 230 & 1250 & 160 & 1050 & 105 & 825 \\
\hline & 100 & 380 & 1950 & 270 & 1650 & 170 & 1375 \\
\hline & 160 & 520 & 2550 & 390 & 2150 & 242 & 1925 \\
\hline & 250 & 780 & 3500 & 550 & 3000 & 345 & 2585 \\
\hline & 400 & 1120 & 4900 & 790 & 4150 & 495 & 3575 \\
\hline & 630 & 1450 & 6650 & 1100 & 5500 & 690 & 5060 \\
\hline & 800 & 1750 & 8700 & 1300 & 7000 & 750 & 6600 \\
\hline & 1000 & 2000 & 10500 & 1450 & 8900 & 885 & 8360 \\
\hline & 1250 & 2250 & 13000 & 1750 & 11500 & 1095 & 10450 \\
\hline & 1600 & 2800 & 17000 & 2200 & 14500 & 1380 & 13200 \\
\hline
\end{tabular}


2016 y1lı Elektrik piyasası raporuna göre Türkiye'deki toplam 436.299 adet dağıtım transformatörü sayısı dikkate alındığında, transformatörlerdeki en küçük iyileştirmenin bile $\mathrm{CO}_{2}$ emisyonun azaltılmasına da faydası olacağ bir gerçektir. Transformatör kayıplarını azaltmanın $\mathrm{CO}_{2}$ emisyonu üzerinde nasıl bir fayda sağlayacağ 1 çalışmasında detaylı olarak incelenmişti [4]. Bu çalışmada, yüksek verimli transformatörlerin, dağıtım şebekesinde kullanılan ve 2005 ve öncesi imal yılına sahip transformatörlerle değişiminin kamu ve özel şirketlere göre yatırım geri dönüş sürelerinin sonuçları sunulacaktır.

\section{TRANSFORMATÖR KAYIPLARINDAKİ DEĞISŞIM}

$33 \mathrm{kV}, \quad 50 \mathrm{kVA}$ dağıtım transformatörün ilk yayınlanan şartnamede boşta kaybı $230 \mathrm{~W}$ yükteki kaybı 1250 W iken Nisan 2018'de boştaki kaybı
105 W yükteki kaybı 825 W olacaktır. Boştaki kayıptaki değişim \%54 iken yükteki değişim \%20'dir. Boştaki kayıplar yüklenmeden bağımsızdır ve transformatör enerjili kaldığı sürece bu kayıp olacaktır. Yükteki kayıplar ise yüke bağımlıdır transformatör yüklendikçe yükteki kayıp artmaktadır. Örneğin; 2005 imal yılına sahip bir dağıtım transformatörünün $\% 50$ yükte transformatörün hem boşta çalışma kaybı hem de $\% 50$ yükteki çalışma kaybı vardır. 2005 ve öncesi imal yılına sahip dağıtım transformatörlerinin yüklenme (\%) durumlarına göre transformatör kayıplarındaki güç kaybı değişimi (W) Çizelge 2'de görülmektedir. Transformatör güçleri büyüdükçe verimleri artmaktadır. Örneğin, 2005 yılında üretilmiş bir $33 \mathrm{kV}, 100 \mathrm{kVA}$ bir transformatörün $\% 50$ yükteki kaybı toplam gücünün $\% 0,87$ 'si iken $33 \mathrm{kV}, 1000 \mathrm{kVA}$ bir transformatörde $\% 0,46$ 'sıdır.

Çizelge 2. Üretim yılı 2005 ve öncesi transformatörlerin doluluk oranına göre kayıplardaki değişim

\begin{tabular}{|c|c|c|c|c|c|c|c|c|c|c|c|c|c|c|}
\hline \multirow[b]{2}{*}{$\mathrm{kV}$} & \multirow{2}{*}{$\begin{array}{c}\text { Güç } \\
\text { (kVA) }\end{array}$} & \multicolumn{2}{|c|}{ Kayıplar(W) } & \multicolumn{11}{|c|}{ Yüklenme Oranına Göre Kayıplardaki Değişim (W) } \\
\hline & & $\begin{array}{c}\text { Boşta } \\
\text { (P0) }\end{array}$ & $\begin{array}{c}\text { Yükte } \\
(\mathrm{Pk})\end{array}$ & $\% 0$ & $\% 10$ & $\% 20$ & $\% 30$ & $\% 40$ & $\% 50$ & $\% 60$ & $\% 70$ & $\% 80$ & $\% 90$ & $\% 100$ \\
\hline \multirow{10}{*}{15,8} & 50 & 190 & 1100 & 190 & 201 & 234 & 289 & 366 & 465 & 586 & 729 & 894 & 1081 & 1290 \\
\hline & 100 & 320 & 1750 & 320 & 337,5 & 390 & 477,5 & 600 & 757,5 & 950 & 1177,5 & 1440 & 1737,5 & 2070 \\
\hline & 160 & 460 & 2350 & 460 & 483,5 & 554 & 671,5 & 836 & 1047,5 & 1306 & 1611,5 & 1964 & 2363,5 & 2810 \\
\hline & 250 & 650 & 3250 & 650 & 682,5 & 780 & 942,5 & 1170 & 1462,5 & 1820 & 2242,5 & 2730 & 3282,5 & 3900 \\
\hline & 400 & 930 & 4600 & 930 & 976 & 1114 & 1344 & 1666 & 2080 & 2586 & 3184 & 3874 & 4656 & 5530 \\
\hline & 630 & 1300 & 6500 & 1300 & 1365 & 1560 & 1885 & 2340 & 2925 & 3640 & 4485 & 5460 & 6565 & 7800 \\
\hline & 800 & 1500 & 8500 & 1500 & 1585 & 1840 & 2265 & 2860 & 3625 & 4560 & 5665 & 6940 & 8385 & 10000 \\
\hline & 1000 & 1700 & 10500 & 1700 & 1805 & 2120 & 2645 & 3380 & 4325 & 5480 & 6845 & 8420 & 10205 & 12200 \\
\hline & 1250 & 2100 & 13000 & 2100 & 2230 & 2620 & 3270 & 4180 & 5350 & 6780 & 8470 & 10420 & 12630 & 15100 \\
\hline & 1600 & 2600 & 17000 & 2600 & 2770 & 3280 & 4130 & 5320 & 6850 & 8720 & 10930 & 13480 & 16370 & 19600 \\
\hline \multirow{10}{*}{33} & 50 & 230 & 1250 & 230 & 242,5 & 280 & 342,5 & 430 & 542,5 & 680 & 842,5 & 1030 & 1242,5 & 1480 \\
\hline & 100 & 380 & 1950 & 380 & 399,5 & 458 & 555,5 & 692 & 867,5 & 1082 & 1335,5 & 1628 & 1959,5 & 2330 \\
\hline & 160 & 520 & 2550 & 520 & 545,5 & 622 & 749,5 & 928 & 1157,5 & 1438 & 1769,5 & 2152 & 2585,5 & 3070 \\
\hline & 250 & 780 & 3500 & 780 & 815 & 920 & 1095 & 1340 & 1655 & 2040 & 2495 & 3020 & 3615 & 4280 \\
\hline & 400 & 1120 & 4900 & 1120 & 1169 & 1316 & 1561 & 1904 & 2345 & 2884 & 3521 & 4256 & 5089 & 6020 \\
\hline & 630 & 1450 & 6650 & 1450 & 1516,5 & 1716 & 2048,5 & 2514 & 3112,5 & 3844 & 4708,5 & 5706 & 6836,5 & 8100 \\
\hline & 800 & 1750 & 8700 & 1750 & 1837 & 2098 & 2533 & 3142 & 3925 & 4882 & 6013 & 7318 & 8797 & 10450 \\
\hline & 1000 & 2000 & 10500 & 2000 & 2105 & 2420 & 2945 & 3680 & 4625 & 5780 & 7145 & 8720 & 10505 & 12500 \\
\hline & 1250 & 2250 & 13000 & 2250 & 2380 & 2770 & 3420 & 4330 & 5500 & 6930 & 8620 & 10570 & 12780 & 15250 \\
\hline & 1600 & 2800 & 17000 & 2800 & 2970 & 3480 & 4330 & 5520 & 7050 & 8920 & 11130 & 13680 & 16570 & 19800 \\
\hline
\end{tabular}


2018 y1lında üretilecek $33 \mathrm{kV}, 100 \mathrm{kVA}$ bir transformatörün $\% 50$ yükteki kaybı toplam gücünün $\% 0,51$ 'i iken $33 \mathrm{kV}, \quad 1000 \mathrm{kVA}$ transformatörde \%0,30'dur. Çizelge 3'ten 2018'de üretilecek yeni trafolar için yüklenme oranlarına göre toplam kayıpları görülmektedir. Bir transformatör merkezinde 2005 ve öncesi transformatörün 2018 üretimli transformatörlerle değişim sonrası toplam kayıptaki değişim Eşitlik 1 ve 2 ile belirlenebilmektedir.
Yükteki Kayıp $(P K)=(\% K)^{2} x P k d$

P0=Boştaki Kayıp,

$\mathbf{P k}=$ Yükteki Kayıp,

$\% \mathbf{\%}=$ Yüklenme oranı,

Pkd=Kısa devre durumundaki kayıp (maksimum yükteki kayıp),

Kayıplardaki değişim $=$ P0 (2005-2018) + Pk

(2005-2018)

Çizelge 3. Nisan 2018'den sonra üretilecek transformatörlerin doluluk oranına göre kayıplardaki değișim

\begin{tabular}{|c|c|c|c|c|c|c|c|c|c|c|c|c|c|c|}
\hline \multirow{2}{*}{$\begin{array}{l}\text { İşletme } \\
\text { Gerilimi } \\
(\mathrm{kV})\end{array}$} & \multirow{2}{*}{$\begin{array}{c}\text { Güç } \\
(\mathrm{kVA})\end{array}$} & \multicolumn{2}{|c|}{ Kayıplar (W) } & \multicolumn{11}{|c|}{ Yüklenme Oranına Göre Kayıplardaki Değişim (W) } \\
\hline & & $\begin{array}{l}\text { Boșta } \\
\text { (P0) }\end{array}$ & $\begin{array}{l}\text { Yükte } \\
\text { (Pk) }\end{array}$ & $\% 0$ & $\% 10$ & $\% 20$ & $\% 30$ & $\% 40$ & $\% 50$ & $\% 60$ & $\% 70$ & $\% 80$ & $\% 90$ & $\% 100$ \\
\hline \multirow{10}{*}{15,8} & 50 & 90 & 750 & 90 & 98 & 120 & 158 & 210 & 278 & 360 & 458 & 570 & 698 & 840 \\
\hline & 100 & 145 & 1250 & 145 & 158 & 195 & 258 & 345 & 458 & 595 & 758 & 945 & 1158 & 1395 \\
\hline & 160 & 210 & 1700 & 210 & 227 & 278 & 363 & 482 & 635 & 822 & 1043 & 1298 & 1587 & 1910 \\
\hline & 250 & 300 & 2350 & 300 & 324 & 394 & 512 & 676 & 888 & 1146 & 1452 & 1804 & 2204 & 2650 \\
\hline & 400 & 430 & 3250 & 430 & 463 & 560 & 723 & 950 & 1243 & 1600 & 2023 & 2510 & 3063 & 3680 \\
\hline & 630 & 600 & 4600 & 600 & 646 & 784 & 1014 & 1336 & 1750 & 2256 & 2854 & 3544 & 4326 & 5200 \\
\hline & 800 & 650 & 6000 & 650 & 710 & 890 & 1190 & 1610 & 2150 & 2810 & 3590 & 4490 & 5510 & 6650 \\
\hline & 1000 & 770 & 7600 & 770 & 846 & 1074 & 1454 & 1986 & 2670 & 3506 & 4494 & 5634 & 6926 & 8370 \\
\hline & 1250 & 950 & 9500 & 950 & 1045 & 1330 & 1805 & 2470 & 3325 & 4370 & 5605 & 7030 & 8645 & 10450 \\
\hline & 1600 & 1200 & 12000 & 1200 & 1320 & 1680 & 2280 & 3120 & 4200 & 5520 & 7080 & 8880 & 10920 & 13200 \\
\hline \multirow{10}{*}{33} & 50 & 105 & 825 & 105 & 113 & 138 & 179 & 237 & 311 & 402 & $\begin{array}{l}509 \\
\end{array}$ & 633 & 773 & 930 \\
\hline & 100 & 170 & 1375 & 170 & 184 & 225 & 294 & 390 & 514 & 665 & 844 & 1050 & 1284 & 1545 \\
\hline & 160 & 242 & 1925 & 242 & 261 & 319 & 415 & 550 & 723 & 935 & 1185 & 1474 & 1801 & 2167 \\
\hline & 250 & 345 & 2585 & 345 & 371 & 448 & 578 & 759 & 991 & 1276 & 1612 & 1999 & 2439 & 2930 \\
\hline & 400 & 495 & 3575 & 495 & 531 & 638 & 817 & 1067 & 1389 & 1782 & 2247 & 2783 & 3391 & 4070 \\
\hline & 630 & 690 & 5060 & 690 & 741 & 892 & 1145 & 1500 & 1955 & 2512 & 3169 & 3928 & 4789 & 5750 \\
\hline & 800 & 750 & 6600 & 750 & 816 & 1014 & 1344 & 1806 & 2400 & 3126 & 3984 & 4974 & 6096 & 7350 \\
\hline & 1000 & 885 & 8360 & 885 & 969 & 1219 & 1637 & 2223 & 2975 & 3895 & 4981 & 6235 & 7657 & 9245 \\
\hline & 1250 & 1095 & 10450 & 1095 & 1200 & 1513 & 2036 & 2767 & 3708 & 4857 & 6216 & 7783 & 9560 & 11545 \\
\hline & 1600 & 1380 & 13200 & 1380 & 1512 & 1908 & 2568 & 3492 & 4680 & 6132 & 7848 & 9828 & 12072 & 14580 \\
\hline
\end{tabular}

Ülkemizde elektrik birim fiyatları Enerji Piyasası Düzenleme Kurumu (EPDK) tarafindan yayınlanmaktadır [5]. Elektrik birim fiyatları kullanıcıya özel olarak mesken, sanayi ve ticarethane olarak değişim göstermektedir (Çizelge 4).

2005 ve öncesi imal yılına sahip bir dağıtım transformatörünün, Nisan 2018'de üretilecek bir dağıtım transformatörüyle değişimi sonrasında kayıplardaki değişim Çizelge 5'te görülmektedir.
Çizelge 4. Türkiye'de elektrik birim fiyatları (KDV ve vergiler dahil)

\begin{tabular}{|l|l|}
\hline \multicolumn{2}{|l|}{ Tek zamanlı Elektrik Birim Fiyatı } \\
\hline Tarife & Elektrik Fiyatı \\
\hline Sanayi & $0,3624 \mathrm{TL}$ \\
\hline Ticarethane & $0,4152 \mathrm{TL}$ \\
\hline Mesken (Ev) & $0,4117 \mathrm{TL}$ \\
\hline Alçak Gerilim - Tek Zamanlı - 1 kWh \\
\hline
\end{tabular}


Çizelge 5. 2005 ve öncesi imal yılına sahip transformatörlerin Nisan 2018 üretimli transformatörlerle değişimi sonrası kayıplardaki değișim

\begin{tabular}{|c|c|c|c|c|c|c|c|c|c|c|c|c|c|c|}
\hline \multirow{3}{*}{$\begin{array}{c}\text { Değişim } \\
\text { İşletme } \\
\text { Gerilimi } \\
(\mathrm{kV})\end{array}$} & \multirow[b]{3}{*}{$\begin{array}{c}\text { Güç } \\
\text { (kVA) }\end{array}$} & \multirow{2}{*}{\multicolumn{2}{|c|}{ Kayıplar(W) }} & & & & & & & & & & & \\
\hline & & & & \multicolumn{11}{|c|}{ Yüklenme Oranına göre toplam Kayıp(W) } \\
\hline & & $\begin{array}{c}\text { Boşta } \\
\text { (P0) } 2005 \\
\text { ve Öncesi }\end{array}$ & $\begin{array}{c}\text { Boşta } \\
\text { (P0) } \\
2018 \\
\end{array}$ & $\% 0$ & $\% 10$ & $\% 20$ & $\% 30$ & $\% 40$ & $\% 50$ & $\% 60$ & $\% 70$ & $\% 80$ & $\% 90$ & $\% 100$ \\
\hline \multirow{10}{*}{15,8} & 50 & 190 & 90 & 100 & 104 & 114 & 132 & 156 & 188 & 226 & 272 & 324 & 384 & 450 \\
\hline & 100 & 320 & 145 & 175 & 180 & 195 & 220 & 255 & 300 & 355 & 420 & 495 & 580 & 675 \\
\hline & 160 & 460 & 210 & 250 & 257 & 276 & 309 & 354 & 413 & 484 & 569 & 666 & 777 & 900 \\
\hline & 250 & 650 & 300 & 350 & 359 & 386 & 431 & 494 & 575 & 674 & 791 & 926 & 1079 & 1250 \\
\hline & 400 & 930 & 430 & 500 & 514 & 554 & 622 & 716 & 838 & 986 & 1162 & 1364 & 1594 & 1850 \\
\hline & 630 & 1300 & 600 & 700 & 719 & 776 & 871 & 1004 & 1175 & 1384 & 1631 & 1916 & 2239 & 2600 \\
\hline & 800 & 1500 & 650 & 850 & 875 & 950 & 1075 & 1250 & 1475 & 1750 & 2075 & 2450 & 2875 & 3350 \\
\hline & 1000 & 1700 & 770 & 930 & 959 & 1046 & 1191 & 1394 & 1655 & 1974 & 2351 & 2786 & 3279 & 3830 \\
\hline & 1250 & 2100 & 950 & 1150 & 1185 & 1290 & 1465 & 1710 & 2025 & 2410 & 2865 & 3390 & 3985 & 4650 \\
\hline & 1600 & 2600 & 1200 & 1400 & 1450 & 1600 & 1850 & 2200 & 2650 & 3200 & 3850 & 4600 & 5450 & 6400 \\
\hline \multirow{10}{*}{33} & 50 & 230 & 105 & 125 & 129 & 142 & 163 & 193 & 231 & 278 & 333 & 397 & 469 & 550 \\
\hline & 100 & 380 & 170 & 210 & 216 & 233 & 262 & 302 & 354 & 417 & 492 & 578 & 676 & 785 \\
\hline & 160 & 520 & 242 & 278 & 284 & 303 & 334 & 378 & 434 & 503 & 584 & 678 & 784 & 903 \\
\hline & 250 & 780 & 345 & 435 & 444 & 472 & 517 & 581 & 664 & 764 & 883 & 1021 & 1176 & 1350 \\
\hline & 400 & 1120 & 495 & 625 & 638 & 678 & 744 & 837 & 956 & 1102 & 1274 & 1473 & 1698 & 1950 \\
\hline & 630 & 1450 & 690 & 760 & 776 & 824 & 903 & 1014 & 1158 & 1332 & 1539 & 1778 & 2048 & 2350 \\
\hline & 800 & 1750 & 750 & 1000 & 1021 & 1084 & 1189 & 1336 & 1525 & 1756 & 2029 & 2344 & 2701 & 3100 \\
\hline & 1000 & 2000 & 885 & 1115 & 1136 & 1201 & 1308 & 1457 & 1650 & 1885 & 2164 & 2485 & 2848 & 3255 \\
\hline & 1250 & 2250 & 1095 & 1155 & 1181 & 1257 & 1385 & 1563 & 1793 & 2073 & 2405 & 2787 & 3221 & 3705 \\
\hline & 1600 & 2800 & 1380 & 1420 & 1458 & 1572 & 1762 & 2028 & 2370 & 2788 & 3282 & 3852 & 4498 & 5220 \\
\hline
\end{tabular}

\section{TRANSFORMATÖRLERIN DEĞISSIMI SONRASI ELDE EDİLECEK KARIN HESAPLANMASI}

Nisan 2018 üretimli verimli transformatörlerin mevcut 2005 ve öncesi imal yılına sahip transformatörlerle değişiminin sanayi aboneleri için Türk Lirası karşılığı Çizelge 6'da görülmektedir. Ortalama \%60 yüke sahip ve imal y1lı 2005 veya daha eski bir $33 \mathrm{kV}, 1000 \mathrm{kVA}$ transformatörün, 2018 üretimli bir transformatörlerle değişimi sonrası bir yılda 5.985 TL kar edilecektir.

Bir Yılda Elde Edilecek Kar $=(($ Kayıplardaki Toplam Değişim/1000)) * 24(saat) * 365 Gün * Sanayi Birim Fiyat
Sanayi Abonesi: \%60 yüklü bir 33kV, 1000 kVA transformatör için;

Sanayi birim fiyat $(\mathrm{kWh})=0,3624 \mathrm{TL}, \% 60$ yükteki kaybı=1885,4 Watt,

Bir yılda elde edilecek;

$\operatorname{Kar}=((1885,4 / 1000) * 24 * 365 * 0,3624)=5985 \mathrm{TL}$

Mesken Abonesi: \%60 yüklü bir 33kV, 1000 kVA Transformatör için;

Mesken birim fiyat $(\mathrm{kWh})=0,4117$ TL, \%60 yükteki kaybı=1885,4 Watt.

Bir yılda elde edilecek;

$\operatorname{Kar}=((1885,4 / 1000) * 24 * 365 * 0,4117)=6799 \mathrm{TL}$. 
Çizelge 6. Sanayi aboneleri 2005 ve öncesi imal yılına sahip transformatörlerin Nisan 2018 üretimli transformatörlerle değişimi sonrası bir yılda elde edilecek kar

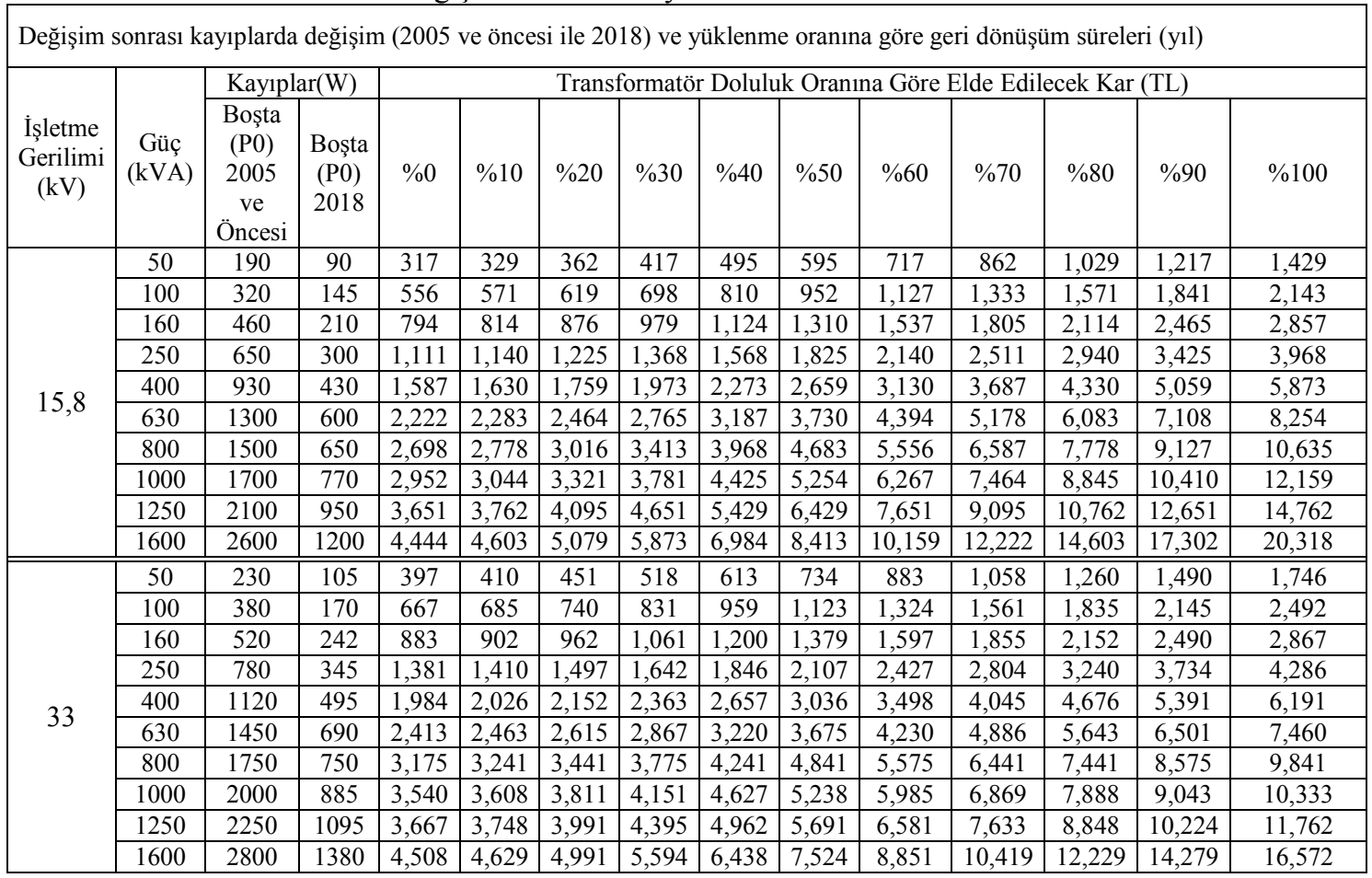

Türkiye'de elektriksel malzemelerin tutarları, montaj bedelleri Türkiye Elektrik Dağıtım A.Ş (TEDAŞ) tarafindan yayınlanan birim fiyatlar kitabında yer almaktadır. TEDAŞ her yıl için birim fiyatları güncellemektedir. TEDAŞ'ın yayınladığ 2016 y1lı Transformatörler birim fiyatlar Çizelge 7'de görülmektedir.

Nisan 2018'de üretilmeye başlanacak transformatörlerin boşta ve yükteki kayıplarının azaltılması için nüve ve bobin tasarımları değişecek ve yeni teknoloji yatırımları gerekecektir. $\mathrm{Bu}$ durum transformatör fiyatlarında artışa sebep olacaktır. Yeni teknoloji maliyeti ve enflasyonun transformatör birim fiyatlarında \%40’lık bir artış yapacağı ön görülmektedir. Eşitlik 4, Çizelge 9 ve Çizelge 10'da YGDS hesabı için kullanılmıştır. Eski trafonun hurda bedeli yatırım geri dönüş süresinde pozitif etkiye sebep olurken, yeni teknoloji maliyeti birim fiyatta artışa sebep olmaktadır.
Çizelge 7. TEDAŞ 2016 ve 2018 için öngörülen transformatör birim fiyatları

\begin{tabular}{|c|c|c|c|}
\hline $\begin{array}{c}\text { İşletme } \\
\text { Gerilimi }(\mathrm{kV})\end{array}$ & $\begin{array}{c}\text { Güç } \\
\text { (kVA) }\end{array}$ & $\begin{array}{c}\text { Birim } \\
\text { Fiyat (TL) }\end{array}$ & $\begin{array}{c}2018 \text { öngörülen birim } \\
\text { fiyat(TL) }\end{array}$ \\
\hline \multirow{10}{*}{15,8} & 50 & 5.140 & 7.196 \\
\hline & 100 & 6.628 & 9.279 \\
\hline & 160 & 8.927 & 12.498 \\
\hline & 250 & 11.249 & 15.749 \\
\hline & 400 & 13.841 & 19.377 \\
\hline & 630 & 19.798 & 27.717 \\
\hline & 800 & 24.210 & 33.894 \\
\hline & 1000 & 27.406 & 38.368 \\
\hline & 1250 & 30.808 & 43.131 \\
\hline & 1600 & 36.556 & 51.178 \\
\hline \multirow{10}{*}{33} & 50 & 5.752 & 8.053 \\
\hline & 100 & 7.123 & 9.972 \\
\hline & 160 & 9.639 & 13.495 \\
\hline & 250 & 11.863 & 16.608 \\
\hline & 400 & 15.008 & 21.011 \\
\hline & 630 & 21.149 & 29.609 \\
\hline & 800 & 26.581 & 37.213 \\
\hline & 1000 & 29.789 & 41.705 \\
\hline & 1250 & 33.271 & 46.579 \\
\hline & 1600 & 40.008 & 56.011 \\
\hline
\end{tabular}


YGDS $=(($ Birim Fiyat + BFA $)-H F)) /(\% \mathrm{KF})$

YGDS $=$ Yatırım Geri Dönüş Süresi,

$\mathrm{BF}=$ TEDAŞ 2016 Transformatör Birim

Fiyatlar1,

$\mathrm{BFA}=$ Birim fiyattaki artış,

$\mathrm{HF}=$ Eski Transformatörün hurda bedeli,

$\% \mathrm{KF}=$ Transformatörlerin ortalama çalışma oranları (Kullanım Faktörü)

Çizelge 8'de geri dönüşüm süresi hesabında kullanılan transformatörlere ait hurda bedelleri sunulmuştur [6]. Çizelge 9 ve 10 'da ise sırasılyla 2005 ve öncesi imal y1lına sahip transformatörlerin Nisan 2018'den sonra üretilecek transformatörlerle
(4) değişiminin sanayi ve mesken aboneleri göre amortisman süreleri sunulmuştur.

\section{SONUÇLAR}

Enerji verimliliğin büyük öneme sahip olduğu ülkemizde özellikle sanayi kullanıcılarına büyük pay düşmektedir. Bugün orta ölçekli bir sanayi kuruluşu küçük bir mahallenin tükettiği elektriğe eşdeğer enerji tüketimi sahiptir. Şekil 1'den de görüldüğü üzere ülkemizde faturalanan elektrik tüketimin \%42,35'i sanayi kullanıcısıdır [2].

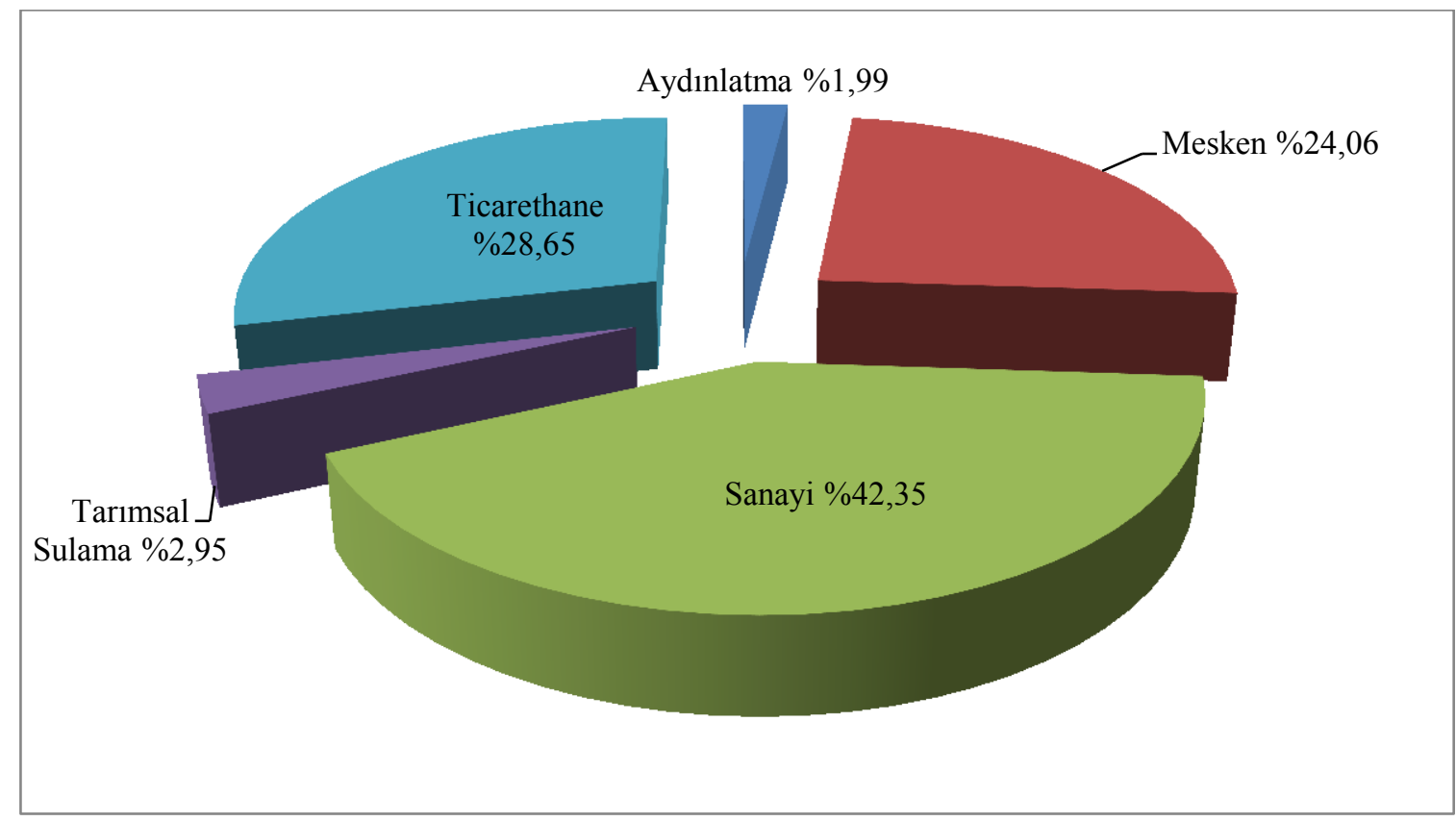

Şekil 1. 2016 yılı faturalanan tüketimin tüketici türüne göre dağılımı

Çizelge 9 detaylı incelendiğinde 2005 ve öncesi imal yılına, yıl boyu ortalama \% 60 doluluğa sahip bir $33 \mathrm{kV}, 1000 \mathrm{kVA}$ sanayi abonesi kullanıcının transformatörünün Nisan 2018 üretimli transformatörle değişiminin amortisman süresi 6,2 yildir.

Transformatörlerin ömürleri sargılarındaki kâğıtlarının ömürleriyle paraleldir. Transformatörlerin faydalı ömürleri 40-50 yıldır ve 6,2 yıllık amortisman süresi bir dağıtım transformatörü için ideal bir amortisman süresidir [7]. Ülkemizde elektrik kullanıcılarını büyük çoğunluğunun elektrik sayaçları transformatörlerin girişindedir. $\mathrm{Bu}$ durum transformatörler kayıplarının kullanıcının faturasına yansımasına sebep olmaktadır. Yüksek verimli transformatörlerin kullanılmasıyla birlikte transformatör teknik kayıpları azaltılarak; enerji verimliliği, ekonomik tasarruf ve çevresel etkilerin azaltılması konularında önemli kazançlar sağlanmış olunacaktır. 
Çizelge 8. Transformatörlerin hurda bedelleri [6]

\begin{tabular}{|c|c|c|c|c|c|c|}
\hline $\begin{array}{c}\text { İşletme gerilimi } \\
\text { kV }\end{array}$ & $\begin{array}{l}\text { Güç } \\
\text { (kVA) }\end{array}$ & $\begin{array}{l}\text { Aktif kısım } \\
\text { ağırlığı } 1(\mathrm{~kg})\end{array}$ & $\begin{array}{l}\text { Yağ ağırllı̆̆ } \\
(\mathrm{kg})\end{array}$ & Toplam (kg) & $\begin{array}{l}\text { Hurda birim fiyatlar } \\
(\mathrm{kg} / \mathrm{TL})\end{array}$ & $\begin{array}{l}\text { Hurda bedeli } \\
\text { (TL) }\end{array}$ \\
\hline \multirow{10}{*}{15,8} & 50 & 360 & 145 & 580 & \multirow{10}{*}{1,58} & 916,4 \\
\hline & 100 & 551 & 210 & 875 & & 1382,5 \\
\hline & 160 & 731 & 248 & 1125 & & 1777,5 \\
\hline & 250 & 930 & 360 & 1500 & & 2370 \\
\hline & 400 & 1360 & 505 & 2195 & & 3468,1 \\
\hline & 630 & 1730 & 604 & 2745 & & 4337,1 \\
\hline & 800 & 2190 & 663 & 3318 & & 5242,44 \\
\hline & 1000 & 2450 & 856 & 3890 & & 6146,2 \\
\hline & 1250 & 2452 & 925 & 4020 & & 6351,6 \\
\hline & 1600 & 3248 & 1152 & 5240 & & 8279,2 \\
\hline \multirow{10}{*}{33} & 50 & 320 & 130 & 510 & \multirow{10}{*}{1,58} & 805,8 \\
\hline & 100 & 470 & 180 & 740 & & 1169,2 \\
\hline & 160 & 665 & 230 & 1015 & & 1603,7 \\
\hline & 250 & 765 & 305 & 1230 & & 1943,4 \\
\hline & 400 & 1000 & 380 & 1590 & & 2512,2 \\
\hline & 630 & 1400 & 505 & 2220 & & 3507,6 \\
\hline & 800 & 1805 & 550 & 2715 & & 4289,7 \\
\hline & 1000 & 1850 & 665 & 2935 & & 4637,3 \\
\hline & 1250 & 2055 & 785 & 3345 & & 5285,1 \\
\hline & 1600 & 2375 & 840 & 3495 & & 5522,1 \\
\hline
\end{tabular}

Çizelge 9. 2005 ve Öncesi imal yılına sahip transformatörlerin Nisan 2018'den sonra üretilecek Transformatörlerle değișiminin sanayi aboneleri göre amortisman süreleri

\begin{tabular}{|c|c|c|c|c|c|c|c|c|c|c|c|c|c|c|c|}
\hline \multicolumn{16}{|c|}{ Sanayi Aboneleri İçin Değișim Sonrası Amortisman Süresi (YIL) } \\
\hline \multirow{2}{*}{$\begin{array}{l}\text { İsletme } \\
\text { gerilimi } \\
(\mathrm{kV})\end{array}$} & \multirow{2}{*}{$\begin{array}{l}\text { Güç } \\
\text { kVA }\end{array}$} & \multirow{2}{*}{$\begin{array}{c}2018 \\
\text { birim } \\
\text { fiyat (TL) }\end{array}$} & \multirow{2}{*}{$\begin{array}{c}\text { Eski } \\
\text { trafonun } \\
\text { hurda } \\
\text { bedeli (TL) }\end{array}$} & \multirow{2}{*}{$\begin{array}{c}\text { Son birim } \\
\text { fiyat } \\
\text { (TL) }\end{array}$} & \multicolumn{11}{|c|}{ Transformatör doluluk oranına göre amortisman süreleri (y1l) } \\
\hline & & & & & $\% 0$ & $\% 10$ & $\% 20$ & $\% 30$ & $\% 40$ & $\% 50$ & $\% 60$ & $\% 70$ & $\% 80$ & $\% 90$ & $\% 100$ \\
\hline \multirow{10}{*}{15,8} & 50 & 7,196 & 916 & 6,280 & 19,8 & 19,1 & 17,4 & 15,0 & 12,7 & 10,5 & 8,8 & 7,3 & 6,1 & 5,2 & 4,4 \\
\hline & 100 & 9,279 & 1,383 & 7,897 & 14,2 & 13,8 & 12,8 & 11,3 & 9,8 & 8,3 & 7,0 & 5,9 & 5,0 & 4,3 & 3,7 \\
\hline & 160 & 12,498 & 1,778 & 10,720 & 13,5 & 13,2 & 12,2 & 10,9 & 9,5 & 8,2 & 7,0 & 5,9 & 5,1 & 4,3 & 3,8 \\
\hline & 250 & 15,749 & 2,370 & 13,379 & 12,0 & 11,7 & 10,9 & 9,8 & 8,5 & 7,3 & 6,3 & 5,3 & 4,6 & 3,9 & 3,4 \\
\hline & 400 & 19,377 & 3,468 & 15,909 & 10,0 & 9,8 & 9,0 & 8,1 & 7,0 & 6,0 & 5,1 & 4,3 & 3,7 & 3,1 & 2,7 \\
\hline & 630 & 27,717 & 4,337 & 23,380 & 10,5 & 10,2 & 9,5 & 8,5 & 7,3 & 6,3 & 5,3 & 4,5 & 3,8 & 3,3 & 2,8 \\
\hline & 800 & 33,894 & 5,242 & 28,652 & 10,6 & 10,3 & 9,5 & 8,4 & 7,2 & 6,1 & 5,2 & 4,3 & 3,7 & 3,1 & 2,7 \\
\hline & 1000 & 38,368 & 6,146 & 32,222 & 10,9 & 10,6 & 9,7 & 8,5 & 7,3 & 6,1 & 5,1 & 4,3 & 3,6 & 3,1 & 2,7 \\
\hline & 1250 & 43,131 & 6,352 & 36,780 & 10,1 & 9,8 & 9,0 & 7,9 & 6,8 & 5,7 & 4,8 & 4,0 & 3,4 & 2,9 & 2,5 \\
\hline & 1600 & 51,178 & 8,279 & 42,899 & 9,7 & 9,3 & 8,4 & 7,3 & 6,1 & 5,1 & 4,2 & 3,5 & 2,9 & 2,5 & 2,1 \\
\hline \multirow{10}{*}{33} & 50 & 8,053 & 806 & 7,247 & 18,3 & 17,7 & 16,1 & 14,0 & 11,8 & 9,9 & 8,2 & 6,9 & 5,8 & 4,9 & 4,2 \\
\hline & 100 & 9,972 & 1,169 & 8,803 & 13,2 & 12,9 & 11,9 & 10,6 & 9,2 & 7,8 & 6,6 & 5,6 & 4,8 & 4,1 & 3,5 \\
\hline & 160 & 13,495 & 1,604 & 11,891 & 13,5 & 13,2 & 12,4 & 11,2 & 9,9 & 8,6 & 7,4 & 6,4 & 5,5 & 4,8 & 4,1 \\
\hline & 250 & 16,608 & 1,943 & 14,665 & 10,6 & 10,4 & 9,8 & 8,9 & 7,9 & 7,0 & 6,0 & 5,2 & 4,5 & 3,9 & 3,4 \\
\hline & 400 & 21,011 & 2,512 & 18,499 & 9,3 & 9,1 & 8,6 & 7,8 & 7,0 & 6,1 & 5,3 & 4,6 & 4,0 & 3,4 & 3,0 \\
\hline & 630 & 29,609 & 3,508 & 26,101 & 10,8 & 10,6 & 10,0 & 9,1 & 8,1 & 7,1 & 6,2 & 5,3 & 4,6 & 4,0 & 3,5 \\
\hline & 800 & 37,213 & 4,290 & 32,924 & 10,4 & 10,2 & 9,6 & 8,7 & 7,8 & 6,8 & 5,9 & 5,1 & 4,4 & 3,8 & 3,3 \\
\hline & 1000 & 41,705 & 4,637 & 37,067 & 10,5 & 10,3 & 9,7 & 8,9 & 8,0 & 7,1 & 6,2 & 5,4 & 4,7 & 4,1 & 3,6 \\
\hline & 1250 & 46,579 & 5,285 & 41,294 & 11,3 & 11,0 & 10,3 & 9,4 & 8,3 & 7,3 & 6,3 & 5,4 & 4,7 & 4,0 & 3,5 \\
\hline & 1600 & 56,011 & 5,522 & 50,489 & 11,2 & 10,9 & 10,1 & 9,0 & 7,8 & 6,7 & 5,7 & 4,8 & 4,1 & 3,5 & 3,0 \\
\hline
\end{tabular}


Çizelge 10. 2005 ve öncesi imal y1lına sahip transformatörlerin Nisan 2018'den sonra üretilecek transformatörlerle değișiminin mesken aboneleri göre amortisman süreleri

\begin{tabular}{|c|c|c|c|c|c|c|c|c|c|c|c|c|c|c|c|}
\hline \multicolumn{16}{|c|}{ Mesken aboneleri için değiş̧im sonrası amortisman süresi (yıl) } \\
\hline \multirow{2}{*}{$\begin{array}{l}\text { İşletme } \\
\text { gerilimi } \\
(\mathrm{kV})\end{array}$} & \multirow{2}{*}{$\begin{array}{c}\text { Güç } \\
\text { (kVA) }\end{array}$} & \multirow{2}{*}{$\begin{array}{c}2018 \\
\text { öngörülen } \\
\text { birim fiyat } \\
\text { (TL) }\end{array}$} & \multirow{2}{*}{$\begin{array}{l}\text { Eski trafonun } \\
\text { hurda bedeli } \\
\text { (TL) }\end{array}$} & \multirow{2}{*}{$\begin{array}{l}\text { Son birim } \\
\text { fiyat (TL) }\end{array}$} & \multicolumn{11}{|c|}{ Transformatör doluluk oranına göre amortisman süreleri (y1l) } \\
\hline & & & & & $\% 0$ & $\% 10$ & $\% 20$ & $\% 30$ & $\% 40$ & $\% 50$ & $\% 60$ & $\% 70$ & $\% 80$ & $\% 90$ & $\% 100$ \\
\hline \multirow{10}{*}{15,8} & 50 & 7,196 & 916 & 6,280 & 17,4 & 16,8 & 15,3 & 13,2 & 11,2 & 9,3 & 7,7 & 6,4 & 5,4 & 4,5 & 3,9 \\
\hline & 100 & 9,279 & 1,383 & 7,897 & 12,5 & 12,2 & 11,2 & 10,0 & 8,6 & 7,3 & 6,2 & 5,2 & 4,4 & 3,8 & 3,2 \\
\hline & 160 & 12,498 & 1,778 & 10,720 & 11,9 & 11,6 & 10,8 & 9,6 & 8,4 & 7,2 & 6,1 & 5,2 & 4,5 & 3,8 & 3,3 \\
\hline & 250 & 15,749 & 2,370 & 13,379 & 10,6 & 10,3 & 9,6 & 8,6 & 7,5 & 6,5 & 5,5 & 4,7 & 4,0 & 3,4 & 3,0 \\
\hline & 400 & 19,377 & 3,468 & 15,909 & 8,8 & 8,6 & 8,0 & 7,1 & 6,2 & 5,3 & 4,5 & 3,8 & 3,2 & 2,8 & 2,4 \\
\hline & 630 & 27,717 & 4,337 & 23,380 & 9,3 & 9,0 & 8,4 & 7,4 & 6,5 & 5,5 & 4,7 & 4,0 & 3,4 & 2,9 & 2,5 \\
\hline & 800 & 33,894 & 5,242 & 28,652 & 9,3 & 9,1 & 8,4 & 7,4 & 6,4 & 5,4 & 4,5 & 3,8 & 3,2 & 2,8 & 2,4 \\
\hline & 1000 & 38,368 & 6,146 & 32,222 & 9,6 & 9,3 & 8,5 & 7,5 & 6,4 & 5,4 & 4,5 & 3,8 & 3,2 & 2,7 & 2,3 \\
\hline & 1250 & 43,131 & 6,352 & 36,780 & 8,9 & 8,6 & 7,9 & 7,0 & 6,0 & 5,0 & 4,2 & 3,6 & 3,0 & 2,6 & 2,2 \\
\hline & 1600 & 51,178 & 8,279 & 42,899 & 8,5 & 8,2 & 7,4 & 6,4 & 5,4 & 4,5 & 3,7 & 3,1 & 2,6 & 2,2 & 1,9 \\
\hline & & & & & & & & & & & & & & & \\
\hline \multirow{10}{*}{33} & 50 & 8,053 & $806 €$ & 7,247 & 16,1 & 15,5 & 14,2 & 12,3 & 10,4 & 8,7 & 7,2 & 6,0 & 5,1 & 4,3 & 3,7 \\
\hline & 100 & 9,972 & 1,169 & 8,803 & 11,6 & 11,3 & 10,5 & 9,3 & 8,1 & 6,9 & 5,9 & 5,0 & 4,2 & 3,6 & 3,1 \\
\hline & 160 & 13,495 & 1,604 & 11,891 & 11,9 & 11,6 & 10,9 & 9,9 & 8,7 & 7,6 & 6,6 & 5,6 & 4,9 & 4,2 & 3,7 \\
\hline & 250 & 16,608 & 1,943 & 14,665 & 9,3 & 9,2 & 8,6 & 7,9 & 7,0 & 6,1 & 5,3 & 4,6 & 4,0 & 3,5 & 3,0 \\
\hline & 400 & 21,011 & 2,512 & 18,499 & 8,2 & 8,0 & 7,6 & 6,9 & 6,1 & 5,4 & 4,7 & 4,0 & 3,5 & 3,0 & 2,6 \\
\hline & 630 & 29,609 & 3,508 & 26,101 & 9,5 & 9,3 & 8,8 & 8,0 & 7,1 & 6,3 & 5,4 & 4,7 & 4,1 & 3,5 & 3,1 \\
\hline & 800 & 37,213 & 4,290 & 32,924 & 9,1 & 8,9 & 8,4 & 7,7 & 6,8 & 6,0 & 5,2 & 4,5 & 3,9 & 3,4 & 2,9 \\
\hline & 1000 & 41,705 & 4,637 & 37,067 & 9,2 & 9,0 & 8,6 & 7,9 & 7,1 & 6,2 & 5,5 & 4,8 & 4,1 & 3,6 & 3,2 \\
\hline & 1250 & 46,579 & 5,285 & 41,294 & 9,9 & 9,7 & 9,1 & 8,3 & 7,3 & 6,4 & 5,5 & 4,8 & 4,1 & 3,6 & 3,1 \\
\hline & 1600 & 56,011 & 5,522 & 50,489 & 9,9 & 9,6 & 8,9 & 7,9 & 6,9 & 5,9 & 5,0 & 4,3 & 3,6 & 3,1 & 2,7 \\
\hline
\end{tabular}

\section{KAYNAKLAR}

1. Nalkaçan, S., 2016. A Sınıfı Kayıplı Transformatörler, Electrotech Dijital Dergisi, Aralık 2017.

2. Elektrik Piyasası 2016 Yılı Piyasa Gelişim Raporu, 2016.

3. TEDAŞ, Malzeme Teknik Şartnameleri. http://www.tedas.gov.tr/\#!tedas_sartnameler_ar ge Aralık 2017.

4. Zağl1, M., 2011. Transformatörlerde Enerji Verimliliği ve Çevresel Etkisi, İyileştirme Boyutları, EMO II. Elektrik Tesisat Ulusal Kongresi Bildirileri, 2011.

5. Enerji Piyasası Düzenleme Kurulu, http:/www.epdk.org.tr/TR/Dokumanlar/TDB/ Elektrik, Aralık 2017.

6. Transformatör Elektro Mekanik Şirketi http://www.betatransformer.com/, Aralık 2017.

7. Haliloğlu, A., 2017. Yük Harmoniklerinin Yağlı Tip Güç Transformatörlerindeki Sıcak Nokta Sicaklığına Dinamik Termal Model Üzerindeki Etkisi, EMO, Aralık 2017. 
